\title{
A scabies outbreak in a diabetic and collagen disease ward: Management and prevention
}

\author{
KENTA FURUYA $^{1}$, HITOSHI NAKAJIMA ${ }^{1}$, YOUSUKE SASAKI $^{1}$, AKIRA ISHIKO ${ }^{2}$ and YOSHIHISA URITA $^{1}$ \\ Departments of ${ }^{1}$ General Medicine and Emergency Care and ${ }^{2}$ Dermatology, Toho University School of Medicine, \\ Omori Hospital, Ota-ku, Tokyo 143-8541, Japan
}

Received October 2, 2015; Accepted October 5, 2016

DOI: $10.3892 /$ etm.2016.3845

\begin{abstract}
Scabies is an infection caused by Sarcoptes scabiei. In developed countries, scabies remains an important public health problem in hospitals and care facilities among elderly or immunocompromised patients. There are a number of medical providers who have not experienced scabies and there has been confusion surrounding its management and prevention. Therefore, the aim of the present study was to identify the optimal approach for the management and prevention of scabies. A scabies outbreak occurred between June 2014 and October 2014 in the Toho University School of Medicine, Omori Hospital (Tokyo, Japan), and the current study investigates factors concerning the outbreak, such as disease recognition, diagnostic strategy, medical staff experience and correspondence after the outbreak occurred. Six patients were newly diagnosed with scabies including patients, medical staff and family of the medical staff. An infection control committee was implemented and required a follow-up survey of 181 people (144 patients and 37 medical staff). It took $\sim 4$ months to resolve the outbreak. Scabies is highly infectious, and sufficient knowledge is required to care for the patients and prevent the infection of healthy people. In this example, the spread of infection was controlled by prompt action.
\end{abstract}

\section{Introduction}

Scabies is an important health concern in hospitals and care facilities. There is no standardized report about Scabies, and occurrence rates vary in the recent literature from 0.271 to $46 \%$ (1). Although there is less information about mortality, deaths frequently occur due to secondary sepsis (2). There are numerous medical staff who have not experienced

Correspondence to: Dr Kenta Furuya or Dr Hitoshi Nakajima, Department of General Medicine and Emergency Care, Toho University School of Medicine, Omori Hospital, 6-11-1 Omori-Nishi, Ota-ku, Tokyo 143-8541, Japan

E-mail: emmanuelpetit1717@yahoo.co.jp

E-mail: nakaji_ma521@yahoo.co.jp

Key words: scabies outbreak, public health, Sarcoptes scabiei scabies, and there are previous reports that have misdiagnosed it as eczema and senile dermal pruritus, leading to an outbreak because of its highly contagious nature (3-6). Scabies is relatively common in tropical areas and in developing countries because of poor hygiene practices, and war and poverty can be causes of large epidemics (7). However, sometimes epidemics occur in medical institutions in elderly and immune-suppressed patients, even in developed countries. In a previous report, bedridden, living in a nursing home, a higher clinical severity status before admission and a catheter inserted are identified as being significant risk factors for acquiring scabies infection (8). Delayed diagnosis of Norwegian scabies, which is highly infectious, has occurred (9). Ivermectin is used worldwide in oral or injection form . Topical application of $5 \%$ permethrin cream is also popular and the combination of an effective topical treatment and oral ivermectin seems to be most successful (10). The present study describes an outbreak of Norwegian scabies at Toho University School of Medicine, Omori Hospital (Tokyo, Japan). This study demonstrates the need for medical staff education so that the infection can be detected early, and the need of an early referral procedure to a medical specialist.

\section{Materials and methods}

The present epidemiologic study was performed between June 2014 and October 2014 in a diabetic and collagen disease ward at the Toho University School of Medicine, Omori Hospital. Written informed consent was obtained from all patients. The clinical features of scabies patients and a report on a follow-up survey that was conducted by the infection control committee were respectively reviewed. The follow-up survey included the following four steps: i) Contact patients admitted onto the same ward as that of a confirmed case; ii) telephone interviews with all family members of the confirmed cases; iii) instructions to consult a dermatologist from the hospital in person or by telephone for those who have symptoms; and iv) consult a dermatologist from our hospital for all medical staff who worked on the same ward (Fig. 1). The case definition did not include suspected cases and a definitive diagnosis of scabies was confirmed by a dermatologist based on the presence of burrows, eggs and mites that were observed using dermatoscopy or microscopy. 

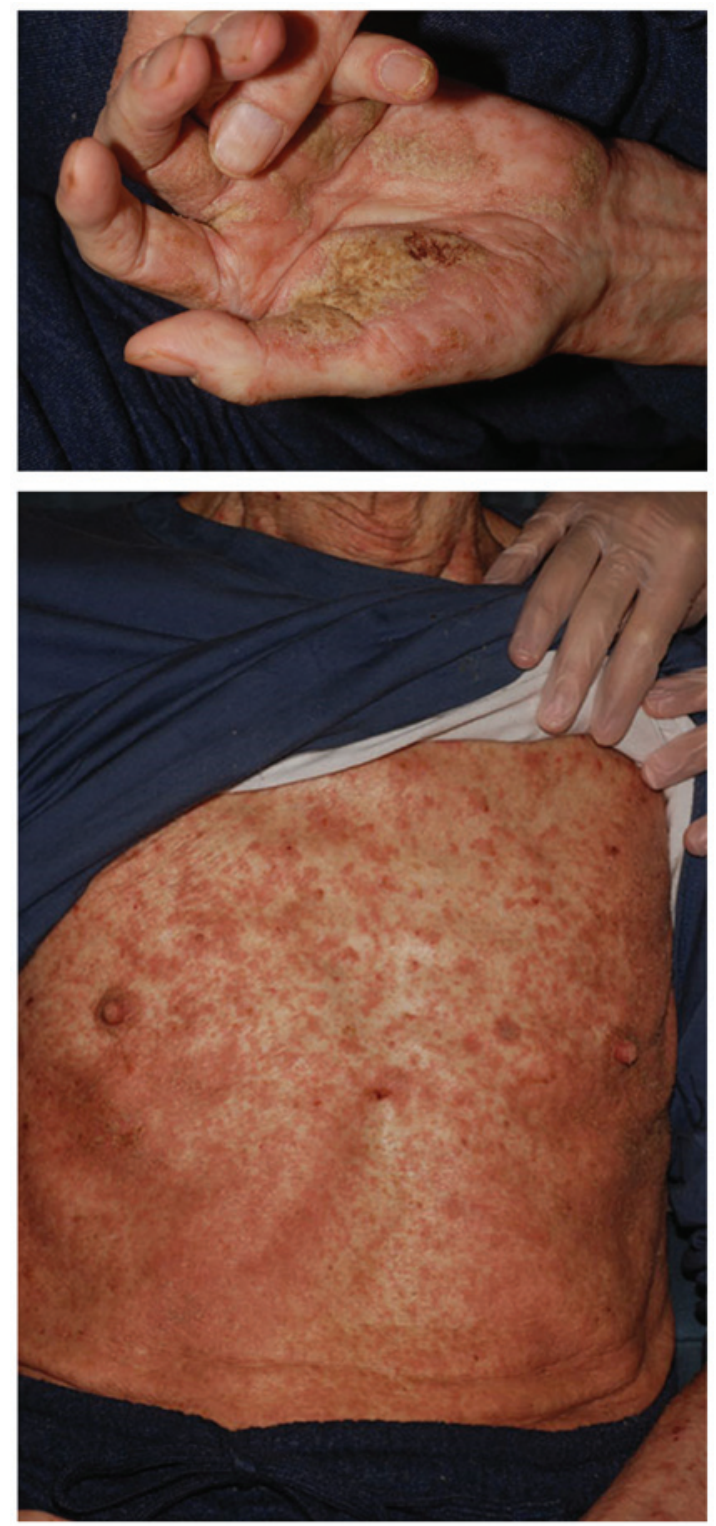

Figure 1. Large hyperkeratotic white and grey plaques were noted on both feet and both hands of patient A. In addition, multiple red pimples were noted on the body trunk.

A suspected case was defined as a person who presents signs and symptoms consistent with scabies, who had direct contact with a confirmed case within the two months preceding the onset of symptoms and who was present in the same room as the first infected patient (patient A). Direct contact with patients with scabies was defined as prolonged hand contact, touching and cleaning of the patient's bed and linen and those who were admitted to the same room as the first infected patient (patient A). All patients who were admitted on the same ward when the scabies patients were hospitalized were located, and medical staff who worked on the same ward during the period the scabies patients were present were considered to be indirect contacts.

Patient A was an 84-year-old male with a history of diabetes. Patient B was a 77-year-old male with a history of diabetes. Patient $\mathrm{C}$ was 79-year-old female receiving corticosteroids for rheumatoid arthritis. Patient D was a 82-year-old male receiving corticosteroids for rheumatoid arthritis.

\section{Results}

This outbreak involved a total of 181 cases among medical staff and patients, and 6 patients developed scabies. It was considered that the absence of burrows, eggs and mites did not eliminate the risk of scabies infestation. Ivermectin (Maruho Co., Ltd., Osaka, Japan) was administered orally as therapeutic administration $(200 \mu \mathrm{g} / \mathrm{kg}$ twice at two-week intervals) in 6 patients and as a preventive (one dose of $200 \mu \mathrm{g} / \mathrm{kg}$ ) in 35 individuals. Phenothrin ointment was applied administered to 6 patients. Patient A, who had been admitted for diabetes, was diagnosed with Norwegian scabies on July 28, 2014 (Fig. 1). An infection control committee was immediately set up when the first cases were diagnosed. The aim was early prophylaxis, surveillance and the completion of treatment. Committee members attended weekly meetings and exchanged information about the progress of patients and the outbreak. The investigation was continued as outlined in the personal and telephone interview flowchart (Fig. 2). During this investigation, two staff (Fig. 3) and 3 patients were newly identified as potentially having Norwegian scabies infection. One of the patients was diagnosed as having Norwegian scabies, and they were admitted for scleroderma (Figs. 4-6). Thus, the outbreak was resolved in three months. During this period, seven relatives of the medical staff developed scabies (Table I). The early resolution is considered to be a result of rapid response to infection.

\section{Discussion}

The present study describes a series of scabies outbreaks in a hospital in Tokyo, Japan. Although worldwide prevalence has been estimated to be $\sim 300$ million cases per year (11), scabies is relatively common in tropical areas and developing countries because of poor hygiene, war and poverty, which has led to large epidemics. Scabies outbreaks can be a serious health problem even in industrialized countries, particularly in schools, prisons, hospitals and in other health care facilities (7). Although a definitive diagnosis is made by dermatoscopy or microscopy, early diagnosis is sometimes made using clinical signs and symptoms (12).

Most of the outbreaks were caused by late diagnosis that resulted from a lack of knowledge and practice, and the opportunity for early diagnosis was missed. Making an early diagnosis can be more difficult in immunosuppressed and elderly patients because they present with atypical symptoms (3), such as hyperkeratotic lesions on the fingertips and nails (13), microvesicular rash and generalized pruritus and hyperkeratosis (14), and hyperpigmented crusted plaques with hemorrhagic fissures (15). Late diagnosis, misdiagnosis or a misleading diagnosis are thought to occur frequently even if dermatologist recommendations are followed, which can lead to outbreaks in medical institutions (16). It is difficult to control this disease once an epidemic occurs, particularly in dementia patients and in facilities where medical staff have insufficient knowledge about scabies. Because the primary symptom of scabies is itching, communication difficulties can sometimes lead to late diagnosis. In addition, less experience and lack of knowledge can contribute to late diagnosis and thereby cause Norwegian scabies epidemics (17). 


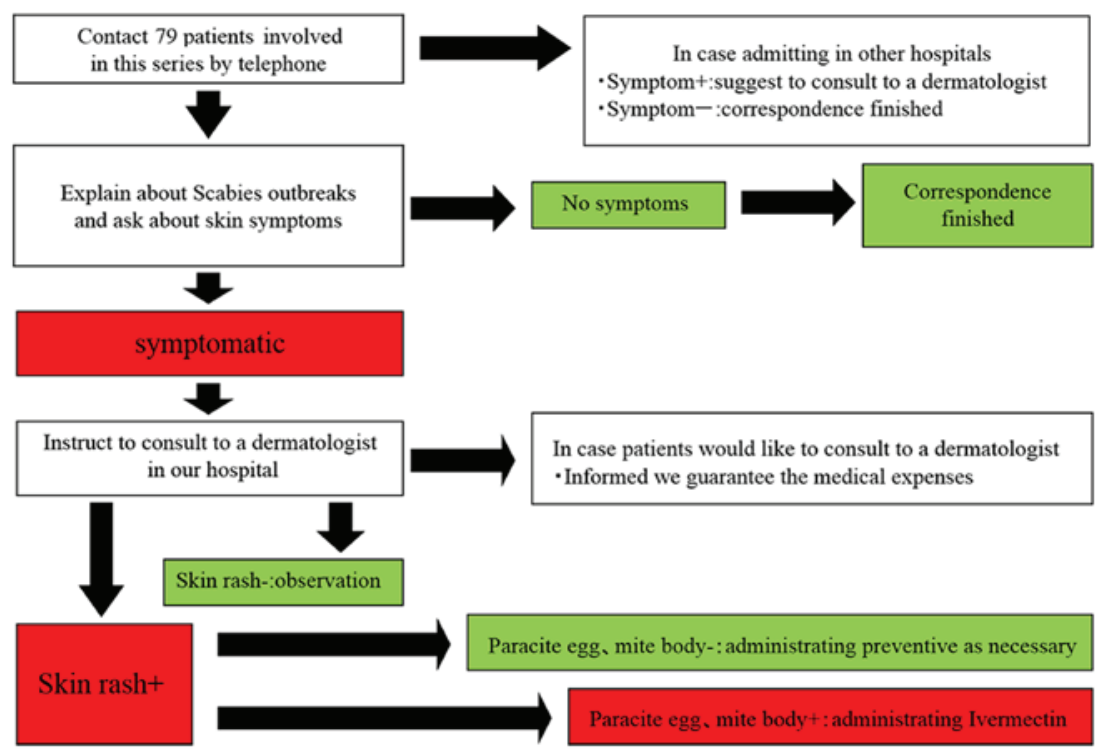

Figure 2. Personal and telephone interview flowchart.

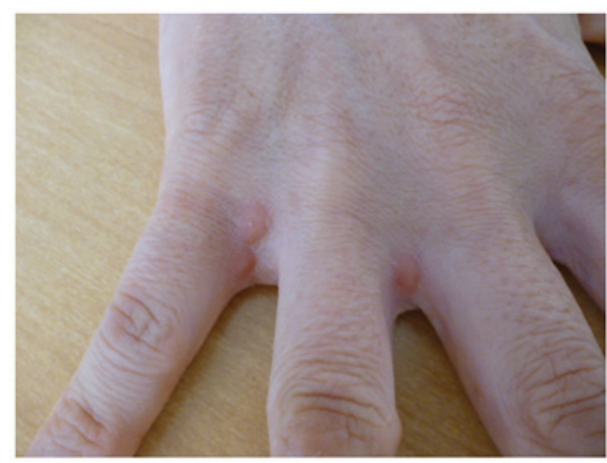

Figure 3. A non-erythematous bullous lesion was seen on a medical staff's (staff A) right hand near the interdigital cleft.
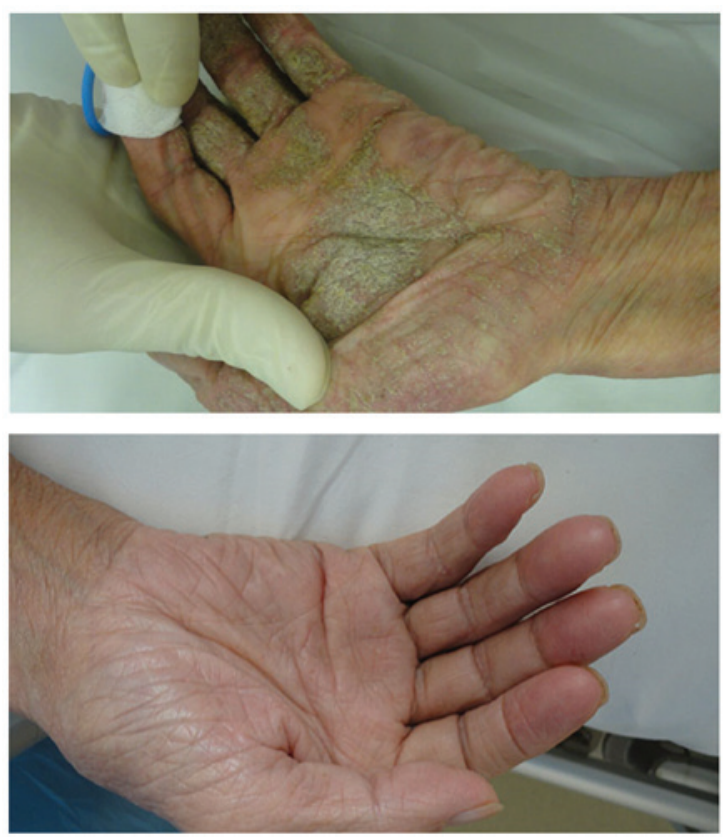

Figure 4. Large hyperkeratotic white and grey plaques were noted on the body trunk, and on both feet and both hands of patient B. This symptom was improved by administering ivermectin.

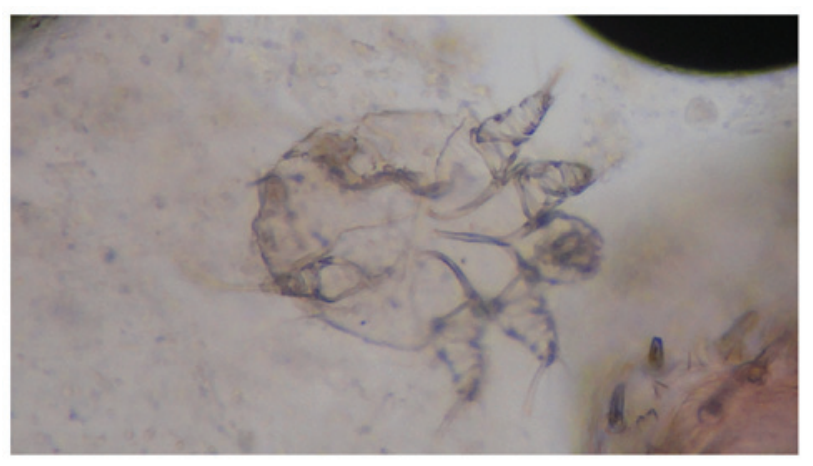

Figure 5. Mite bodies were found on Patient D's hand. Magnification, x200.

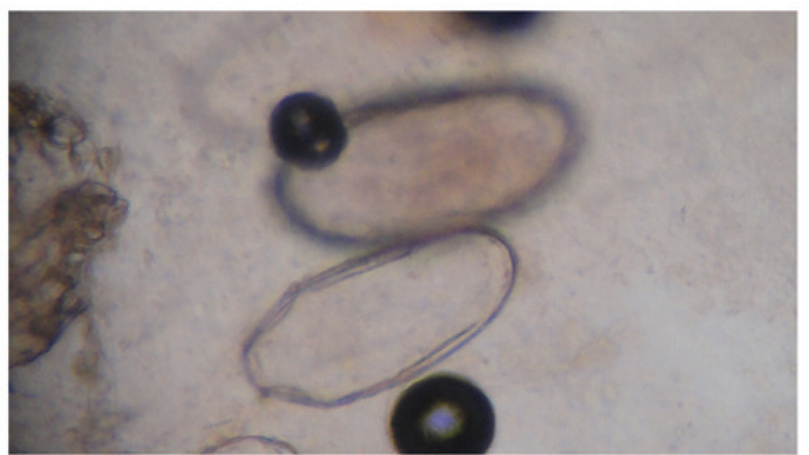

Figure 6. Parasite eggs were found on Patient D's hand. Magnification, x200.

In the present study, the outbreak occurred in a diabetic and collagen disease ward. This type of immune-related disease could be a risk factor for the spread of scabies. It has been reported that there is a higher risk of mortality in patients with complications such as human immunodeficiency virus (HIV)/human T-cell leukemia virus type 1 infection (18). Particular attention should be paid to patients with scabies if they are undergoing immunosuppressive therapy or if they have conditions such as diabetes or HIV (19). In the present study, it 
Table I. Scabies clinical course.

Date Patient situation Infection control committee correspondence

$\begin{array}{ll}06 / 19 & \text { Patient A admitted to health facility } \\ 06 / 23 & \text { Rash appeared on Patient A } \\ 07 / 28 & \text { Patient A diagnosed } \\ & \text { with Norwegian scabies }\end{array}$

09/23 Staff A diagnosed with scabies

09/24 Staff B diagnosed with scabies

$09 / 29$

Patient B, who was admitted during 06/18-07/03, diagnosed with scabies

$10 / 01$

$10 / 03$

Patient $\mathrm{C}$, who was admitted during 06/06-07/15, diagnosed with scabies Patient $\mathrm{D}$ diagnosed with Norwegian scabies

$10 / 16$

$10 / 13$

$10 / 27$

Treatment ended for all medical staff

Treatment ended for all patients
Infection control committee set up

Screened all medical staff and patients admitted in the same room with Patient $\mathrm{A} \rightarrow$ negative Ward closure

- Re-screened all medical staff and patients admitted in the same ward

- Preventive ivermectin administration performed in 2 patients and 33 medical staff

- Informed every medical office and ward

- Informed local public health care center

- Informed every patient who was discharged

Notified by public health care center to confirm the skin condition of patients admitted from the onset to the present time Informed the Ministry of Welfare At this time:

- 4 patients developed scabies

- 2 medical staff developed scabies

- 1 medical staff family member developed

scabies $\rightarrow$ total of 7 patients

Investigation according to personal and telephone interview flowchart completed

Confirmation of outbreak resolution was thought that the spread of infection could be minimized by quick action. There are a number of reports of limited damage and practices that can be followed to control scabies outbreaks in health facilities, and the studies suggest that countermeasures should start immediately in such cases $(12,16)$. In the current study, the authors asked to be involved with the infection control committee in order to gain increased knowledge about the outbreak. Immediate organization of the infection control committee led to quick action and resulted in an early resolution of the outbreak. From this, it can be suggested that each facility needs to establish the management process, and recognize that external support may be required.

In conclusion, once the scabies outbreak occurred, a lot of time and labor was required to contain the outbreak. The education of medical staff to aid early detection, and the establishment of a working system that allows wide-spread early referrals to a medical specialist in suspected cases, can identify and control scabies infection. Education and prompt action can prevent a scabies outbreak.

\section{References}

1. Fuller LC: Epidemiology of scabies. Curr Opin Infect Dis 26: 123-126, 2013.
2. McCarthy JS, Kemp DJ, Walton SF and Currie BJ: Scabies: More than just an irritation. Postgrad Med J 80: 382-387, 2004.

3. Bouvresse $\mathrm{S}$ and Chosidow O: Scabies in healthcare settings. Curr Opin Infect Dis 23: 111-118, 2010.

4. Achtari Jeanneret L, Erard P, Gueissaz F and Malinverni AR: An outbreak of scabies: A forgotten parasitic disease still present in Switzerland. Swiss Med Wkly 137: 695-699, 2007.

5. Scheinfeld N: Controlling scabies in institutional settings: A review of medications, treatment models and implementation. Am J Clin Dermatol 5: 31-37, 2004.

6. Obasanjo OO, Wu P, Conlon M, Karanfil LV, Pryor P, Moler G, Anhalt G, Chaisson RE and Perl TM: An outbreak of scabies in a teaching hospital: Lesson learned. Infect Control Hosp Epidemiol 22: 13-18, 2001.

7. Hay RJ, Steer AC, Chosidow O and Currie BJ: Scabies: A suitable case for a global control initiative. Curr Opin Infect Dis 26: 107-109, 2013.

8. Wang CH, Lee SC, Huang SS, Kao YC, See LC, Yang SH: Risk factors for scabies in Taiwan. J Microbiol Immunol Infect 45: 276-280, 2012.

9. Utsumi M, Makimoto K, Quroshi N and Ashida N: Types of infectious outbreaks and their impact in elderly care facilities: A review of the literature. Age Ageing 39: 299-305, 2010.

10. Meinking TL, Taplin D, Hermida JL, Pardo R and Kerdel FA: The treatment of scabies with ivermectin. N Engl J Med 333: 26-30, 1995.

11. Chosidow O: Clinical practices: Scabies. N Eng1 J Med 354: $1718-1727,2006$

12. Buehlmann M, Beltramineli H, Strub C, Bircher A, Jordan X, Battegay M, Itin P and Widmer AF: Scabies outbreak in an intensive care unit with exposed individuals-key factors for controlling the outbreak. Infect Control Hosp Epidemiol 30: 354-360, 2009. 
13. Del Borgo C, Belvisi V, Tieghi T and Mastroianni CM: Atypical presentation of crusted (Norwegian) scabies. Infection 43: 623-624, 2015

14. Boureau AS, Cozic C, Poiraud C, Varin S, Chaillous B and Cormier G: Does immunodepression induced by TNF antagonists promote atypical scabies? Joint Bone Spine 81: 186-187, 2014.

15. Fernández-Sánchez M, Saeb-Lima M, Alvarado-de la Barrera C and Reyes-Terán G: Crusted scabies-associated immune reconstitution inflammatory syndrome. BMC Infect Dis 12: 323, 2012.

16. Tjioe $M$ and Vissers WH: Scabies outbreaks in nursing homes for the elderly: Recognition, treatment options and control of reinfestation. Drugs Aging 25: 299-306, 2008.
17. Tsutsumi M, Nishiura $H$ and Kobayashi T: Dementia specific risks of scabies: Retrospective epidemiologic analysis of an unveiled nosocomial outbreak in Japan from 1989-90. BMC Infect Diss 5: 85, 2005.

18. Brites C, Weyll M, Pedoroso C and Badaró R: Severe and Norwegian scabies are strongly associated with retroviral (HIV-1/HTLV-1) infection in Bahia, Brazil. AIDS 16: 1292-1293, 2002.

19. Capobussi M, Sabatino G, Donadini A, Tersalvi CA and Castaldi S: Control of scabies outbreaks in an Italian hospital: An information-centered management strategy. Am J Infect Control 42: 316-320, 2014. 